\title{
SALIVARY CORTISOL CHANGES IN CHILDREN DURING DENTAL EXTRACTIONS
}

Vivek Padmanabhan ${ }^{1}$, Kavita Rai², Amitha M. Hegde ${ }^{3}$

\section{HOW TO CITE THIS ARTICLE:}

Vivek Padmanabhan, Kavita Rai, Amitha M. Hegde. "Salivary Cortisol changes in children during Dental Extractions". Journal of Evolution of Medical and Dental Sciences 2014; Vol. 3, Issue 04, January 27; Page: 811814, DOI: $10.14260 /$ jemds/2014/1907

\begin{abstract}
Dental environment may be a source of stress for young children. Such stressful conditions may provoke fear and anxiety in children. Therefore stress factor is high in children visiting dentists and this stress may increase or decrease in the subsequent visits that follow dependent upon to what they are exposed to, during these visits especially high anxiety provoking procedures like dental extractions. Cortisol, called also "stress hormone" participates in organism's response to stress situations and enters into complex interactions with the hormonal and immune system of a man. The salivary cortisol levels were investigated in 60 children who were divided into study and control groups respectively. The control group was not subjected to any treatment except for collection of saliva. Children belonging to the study group were subjected to dental extraction as indicated and were performed in three scheduled appointments. Saliva samples were collected from all the children during all the appointments. Salivary cortisol levels were evaluated using the ELISA kit supplied by Salimetrics. The results indicated that the salivary cortisol levels increased in the study group when compared to the control groups and within the study group the salivary cortisol levels in the second appointment were on a higher level when compared to the first and third appointments.
\end{abstract}

KEYWORDS: Anxiety, Stress, Salivary Cortisol.

INTRODUCTION: Stress is defined as a nonspecific reaction of the body to any request for adjustment or adaptation, performed in a stereotyped manner on the base of identical biochemical changes..$^{1,2}$ Anxiety is one of the many symptoms of the reaction of men to stress situations. ${ }^{3}$

"Oral based diagnostics" is a scientific field developed very actively in recent years. ${ }^{4,5}$ Cortisol, known as a stress hormone, participates in the response of the body to stress conditions and enters into complex interactions with the hormonal and immune system of a man. It participates in the most complex hormonal system, known as hypothalamus-pituitary- adrenal axis.6,7

In a literature review it was found that very few studies are available which show the relationship between dental procedures in children and salivary cortisol levels. Hence, this study was designed so as to compare the levels of salivary cortisol in children when exposed to the commonest of the dental procedure like extractions.

MATERIALS AND METHODS: 60 children aged 5-9 years, who reported to the department of Pediatric and Preventive Dentistry, A.B. SHETTY MEMORIAL INSTITUTE OF DENTAL SCIENCES, MANGALORE were included in the study. All the children had teeth which were indicated for dental extractions of deciduous and in a very few cases extraction of permanent first molars. The study group had 18 males and 12 females and the control group had 17 males and 13 females. 
For all the children included in the study and control group, the dental health status as part of the diagnosis for dental extractions was assessed using the WHO oral assessment form. ${ }^{8}$ The children belonging to the control group were children who were also indicated for dental extractions, but their treatment would be done on a later date after the study group. During this particular research project time, they would only be used for collection of saliva during the four appointment times.

The children included in the study group were subjected to dental extractions in three scheduled appointments. Informed consent from the parents and all the selected children of both the groups were taken. Patients who were physically and medically compromised and who had arrested carious lesions were excluded. Children who were also on medications especially corticosteroids were also excluded from the study. For the collection of saliva the child was seated in the coachman's position, head slightly down and was asked not to swallow or move his tongue or lips during the period of collection. The saliva was allowed to accumulate in the mouth for 5 minutes and he or she was asked to passively drool the accumulated saliva into the receiving vessel. ${ }^{9} 2 \mathrm{ml}$ of unstimulated saliva was collected and frozen at $-20^{\circ} \mathrm{C}$ until evaluation..$^{9,10}$ All the saliva samples were collected at the same time (between 09 am and 12 noon) on all appointments to rule out any bias owing to the diurnal variations. The salivary cortisol levels were evaluated using Salimetrics ${ }^{\mathrm{TM}}$ cortisol kit (SALIVARY CORTISOL ENZYME IMMUNOASSAY KIT) provided by Salimetrics LLC USA.

Methodology for Dental extractions and saliva collection: All the children of the study group were treated in three appointments. In the first appointment the children were explained about the procedure that they would be undergoing. In the second appointment the dental extraction was performed under local anesthesia. In the third appointment the patient was recalled for a follow up. At the end of each of the above mentioned three appointments saliva was collected for evaluation of cortisol levels

RESULTS: When the salivary cortisol levels were compared between the study and control group as such, it was seen that the cortisol levels were higher in the study group subjected to dental extractions than in the control group who were not subjected to any such treatment (Table 1).

When the whole population involved in the study group was divided into three groups based on the scheduled appointments, it was found that the study groups during the second and third appointments showed significantly higher levels of cortisol in saliva when compared to the first appointment, and these results were statistically significant. (Table 2).

DISCUSSION: When we compared the cortisol levels of saliva in children belonging to the study and control groups, the results suggest an increase in the cortisol levels of saliva in children belonging to the study group as compared to the control groups.

This general difference in the salivary cortisol levels between the study and control groups could be due to the obvious reason that definitely, study group was exposed to dental therapies resulting in an increased level of stress in these children which showed elevated levels of cortisol when compared to the control group who were not subjected to any procedure except for collection of saliva (Table 1). These findings are in accordance with studies done previously suggesting that when put under stress children do show elated levels of salivary cortisol levels. ${ }^{11,12}$ 
When the study group itself is divided into three groups based on the appointments they were subjected to, it was found that the levels were increased profoundly during the second and third appointments when compared to the first appointment and the results were statistically significant (TABLE 2). It is during the second appointment that more fear provoking procedures like the administration of local anesthesia, dental extraction and use of suction was done. During the third appointment most of the children were yet anxious as a result of the second appointment which could also be a reason for the increased levels of anxiety and stress and hence increased salivary cortisol levels.

Also in studies done before this research to evaluate salivary cortisol levels, it was suggested that there is an increase of cortisol levels during the stages when children were subjected to dental treatment 11,12 , and 13

The difference in salivary cortisol levels between males and females could not be established from this study as it was not the objective but it definitely has scope in future studies.

Though there is literature which suggest that the appearance of the dentist and also the operatory are factors which can influence the behavior of the child, our study also reveals that apart from the appearance and the behavior of the dental team, it may also be necessary to have a serene and silent environment when compared to a noisy dental operatory which can definitely help the child be more calm amongst us and go through his treatment more conveniently and effectively without being stressed.

\begin{tabular}{|c|c|c|c|c|c|c|c|c|c|}
\hline Group & Visit & $\mathrm{N}$ & Mean & SD & Median & Min. & Max. & 'F'value & 'p' value \\
\hline \multirow{3}{*}{ Control Group } & 1st app & 61 & 0.632 & 0.0561 & 0.650 & 0.50 & 0.72 & \multirow{3}{*}{1.399} & \multirow{3}{*}{0.250} \\
\hline & 2nd app & 61 & 0.640 & 0.0682 & 0.650 & 0.52 & 0.82 & & \\
\hline & 3rd app & 61 & 0.620 & 0.0701 & 0.630 & 0.45 & 0.78 & & \\
\hline \multirow{3}{*}{ Study Group } & 1st app & 60 & 0.648 & 0.0531 & 0.640 & 0.57 & 0.80 & \multirow{3}{*}{126.054} & \multirow{3}{*}{$<0.001$} \\
\hline & 2nd app & 60 & 0.806 & 0.0617 & 0.805 & 0.68 & 0.93 & & \\
\hline & 3rd app & 60 & 0.709 & 0.0486 & 0.700 & 0.59 & 0.82 & & \\
\hline
\end{tabular}

Table 1: salivary cortisol levels between study and control group during different appointments

\begin{tabular}{|c|c|c|c|c|c|c|c|c|}
\hline Visit & Group & $\mathrm{N}$ & Mean & SD & Median & Min. & Max. & 'p' value \\
\hline \multirow{2}{*}{ 1st app } & Control & 61 & 0.632 & 0.0561 & 0.650 & 0.50 & 0.72 & \multirow{2}{*}{0.111} \\
\cline { 2 - 8 } & Study & 60 & 0.648 & 0.0531 & 0.640 & 0.57 & 0.80 & \\
\hline \multirow{2}{*}{ 2nd app } & Control & 61 & 0.640 & 0.0682 & 0.650 & 0.52 & 0.82 & \multirow{2}{*}{$<0.001$} \\
\cline { 2 - 8 } & Study & 60 & 0.806 & 0.0617 & 0.805 & 0.68 & 0.93 & \\
\hline \multirow{2}{*}{ 3rd app } & Control & 61 & 0.620 & 0.0701 & 0.630 & 0.45 & 0.78 & \multirow{2}{*}{$<0.001$} \\
\cline { 2 - 8 } & Study & 60 & 0.709 & 0.0486 & 0.700 & 0.59 & 0.82 & \\
\hline
\end{tabular}

Table 2: salivary cortisol levels between study and control group during each appointment

\section{REFERENCES:}

1. Hans Selie. Stress without distress, 1982 ed. Science and art publications, 1-135.

2. Cohen S, Kessler RC and Gordon LU. Measuring stress: a guide for health and social scientists, oxford university press: 1997; 13(1):67-68. 


\section{ORIGINAL ARTICLE}

3. Ilana Eli. Oral Psychophysiology: Stress, Pain and Behavior in Dental Care, CRC Publications, $1^{\text {st }}$ ed.1992; 72-75.

4. Tabak LA. A revolution in biomedical assessment: the development of salivary diagnostics. J Dent Educ. 2001 Dec; 65(12):1335-9.

5. Malamud D, Tabak LA. Saliva as a diagnostic fluid. Ann NY Acad Sciences 1993; 1-694.

6. Gozansky W.S., Lynn J.S., Laudenslager M.L. and Kohrt W.M. Salivary cortisol determined by enzyme immunoassay is preferable to serum total cortisol for assessment of dynamic hypothalamic-pituitary-adrenal axis activity. Clin Endocrinol (Oxf), 2005, 63(3): 336-41.

7. Schwartz E. B., Granger D. A., Susman E. J., Gunnar M. R., Laird B. Assessing salivary cortisol in studies of child development. Child Development, 1998; 69(6):1503-1513.

8. World Health Organization. Oral Health Surveys: Basic Methods; 4th Ed: Geneva: WHO; 1996.

9. Tenovuo J. Salivary parameters of relevance for assessing caries activity in individuals and populations. Community Dental Oral Epidemiol.1997; 25:82-86.

10. Gusenoff JA et al. Cortisol and GH secretory dynamics and their interrelationships in Healthy Aged Women and Men. Am J of Physiol Endocrinol Metab.2001; 280:E616-625.

11. Blomqvist $M$ et al. Salivary cortisol levels and dental anxiety in children with attention deficit hyperactivity disorder. Eur J Oral Sci.2007; 115(1):1-6.

12. Kanegane $\mathrm{K}$ et al. Dental anxiety and salivary cortisol levels before urgent dental care. J Oral Sci.2009; 51(4):515-20.

13. Greabu M et al. Salivary Cortisol- Marker of stress response to different dental treatment. Rom J Intern Med.2006; 44(1):49-59.

\section{AUTHORS:}

1. Vivek Padmanabhan

2. Kavita Rai

3. Amitha M. Hegde

\section{PARTICULARS OF CONTRIBUTORS:}

1. PhD Student, Department of Pedodontics and Preventive Dentistry, A.B. Shetty Memorial Institute of Dental Sciences, Mangalore, Karnataka, India.

2. Professor, Department of Pedodontics and Preventive Dentistry, A.B. Shetty Memorial Institute of Dental Sciences, Mangalore, Karnataka, India.

3. Professor and HOD, Department of Pedodontics and Preventive Dentistry, A.B. Shetty Memorial Institute of Dental Sciences, Mangalore, Karnataka, India.

\section{NAME ADDRESS EMAIL ID OF THE CORRESPONDING AUTHOR:}

Dr. Vivek Padmanabhan, Department of Pedodontics and Preventive Dentistry,

A.B. Shetty Memorial Institute of Dental Sciences, Mangalore, Karnataka, India.

E-mail: vivek_pdr@rediffmail.com
Date of Submission: 05/01/2014. Date of Peer Review: 06/01/2014. Date of Acceptance: 16/01/2014. Date of Publishing: 21/01/2014. 